EGU2020-20720

https://doi.org/10.5194/egusphere-egu2020-20720

EGU General Assembly 2020

(c) Author(s) 2021. This work is distributed under

the Creative Commons Attribution 4.0 License.

\title{
Comparison of coupling methods in joint inversion along the Namibian continental margin
}

\author{
Gesa Franz ${ }^{1}$, Max Moorkamp ${ }^{2}$, Marion Jegen ${ }^{1}$, Christian Berndt ${ }^{1}$, and Wolfgang Rabbel ${ }^{3}$ \\ ${ }^{1}$ Geomar Helmholtz Centre for Ocean Research Kiel, Marine Geodynamics, Germany (gfranz@geomar.de) \\ ${ }^{2}$ Department of Earth and Environmental Sciences, Geophysics, Munich University, Germany \\ ${ }^{3}$ Institute of Geosciences, Applied Geophysics, Kiel University, Germany
}

Understanding the driving mechanisms of continental breakup is still a key question in global geodynamics. The Namibian continental margin and Walvis Ridge offer an ideal area for related studies, because it accumulates on- and offshore magmatic features, associated with crustal stretching, a potential plume impact, and continental breakup.

While previous studies in the area all agree on the general occurrence of these features, they have shown some contradictory results for their extent and depth. Therefore, we jointly invert different geophysical data sets to gain a deeper, three-dimensional insight into the continent-oceantransition zone. In this study, we test three different cross-gradient coupling approaches for Magnetotelluric, Gravity and Seismic data sets or models. First, a fixed 3D density model is used as a structural constraint to MT data inversion. It's impact is limited, due to large model areas with constant density values, and thus zero density gradients. Second, satellite gravity and MT data are jointly inverted. Both data sets reach a satisfactory misfit and the gravity data constraint slightly modifies the interpreted earth model. Third, a fixed 2D velocity model is used as a structural constraint for a 3D MT data inversion. Some assumptions had to be made to account for the dimensionality difference, but a sufficiently good data fit was achieved, and inversion benefits from a gradient structural model for the cross-gradient coupling. Earth model modifications through this velocity model constraint resemble the results from the joint Gravity-MT data inversion. The analysis of the three approaches, yields new insights into the cross-gradient coupling concept for joint inversion.

Interpreting these three earth models, we believe, that continental break-up in the South Atlantic is neither driven solely by a large plume, nor by pure tectonic forces. High resistivites, velocities and densities in the lower crust point to an accumulation of plume material. However, the size of these features is not big enough to explain the Gondawana break-up as a result of a mega-plume arrival. Indications for a tectonically driven break-up initiation include evidence for extensive crustal stretching, and often an abrupt change to oceanic regime, with the upwelling 
asthenosphere in juxtaposition to the stretched continental lithosphere. As our models indicate a broader transitional zone, we exclude a pure tectonically driven continental break-up. Our favoured explanation incorporates aspects of both hypothesis, where an accumulation of so-called secondary plumes initiate rifting and break-up. These would be smaller plumes, rising from midmantle depths, which might have a common source in the deep mantle. 